\title{
Effects of reinforcement magnitude during successive reinforcement-punishment cycles
}

\author{
DOUGLAS P. FERRARO AND DAVID PERKINS \\ UNIVERSITY OF NEW MEXICO
}

Three rats were exposed to shifts in reinforcement magnitude during successive reinforcement-punishment periods. Rate of response was sensitive to both the prevailing and preceding reinforcement magnitude. Unpunished responding was also dependent on the number of reinforcement-punishment alternations.

Maintained rate of responding in single-manipulandum free-operant situations is apparently insensitive to noncontingent shifts in reinforcement magnitude except where these shifts are correlated with changes in exteroceptive cues (Catania, 1963; Shettleworth \& Nevin, 1965). However, reinforcement magnitude has been shown to affect single-manipulandum responding under stimulus probe, extinction or punishment procedures (Keesey \& Kling, 1961; Shettleworth \& Nevin, 1965; Ferraro, 1966). These findings may be generalized to suggest that non-contingent shifts in reinforcement magnitude will control free-operant response rates if correlated with any change in experimental conditions. In the present experiment, non-contingent shifts in reinforcement magnitude were correlated with the removal of shock punishment during successive reinforcement-punishment cycles. The use of successive periods of reinforcement and punishment made it possible to assess separately any effects of reinforcement magnitude on punished and non-punished behavior. Method

Three 120 day old male Sprague-Dawley rats served as Ss. Each $\mathrm{S}$ was individually housed and maintained on a $24 \mathrm{~h}$ water deprivation rhythm throughout the experiment.

The experimental chamber was a Scientific Prototype rat box equipped with a single response lever and liquid dipper which delivered reinforcements. The chamber floor consisted of seven equally spaced stainless steel grids which were wired to a Grason-Stadler shock generator and scrambler. Punishment consisted of .5 sec of a .25 mA electric shock delivered through the grid floor and response lever.

Following preliminary dipper-approach and barpress training, each $S$ was given 40 consecutive daily $1 \mathrm{~h}$ sessions in which responding was reinforced according to a $1 \mathrm{~min}$ variable-interval (VI) reinforcement schedule. During these initial phases of the experiment, reinforcement consisted of $3 \mathrm{sec}$ access to $.02 \mathrm{cc}$ of water. The Ss were then exposed to 15 successive reinforcement-punishment cycles. Each of the 15 cycles consisted of seven consecutive daily $1 \mathrm{~h}$ sessions of VI $1 \mathrm{~min}$ reinforcement followed by seven consecutive daily $1 \mathrm{~h}$ sessions in which each response emitted under the VI reinforcement schedule was followed by shock. The magnitude of reinforcement was held constant within a reinforcement-punishment cycle. For cycles numbered $3,6,9$ and 12 , reinforcement consisted of $3 \mathrm{sec}$ access to $.06 \mathrm{cc}$ of water. Reinforcement for the other 11 cycles was $3 \mathrm{sec}$ access to $.02 \mathrm{cc}$ of water.

\section{Resulfs}

Figure 1 presents average response rates for the three Ss obtained during each reinforcement-punishment cycle. The full extent of each column in Fig. 1 represents average response rate for the seven day reinforcement phase of a given cycle, while the shaded portion of each column represents average response rate for the succeeding seven day punishment phase of that cycle. As shown in Fig. 1, the introduction of shock punishment during the first punishment phase produced a large reduction in response rate as compared to the pre-punished response rate. However, the reduced response rate obtained during this first and each succeeding punishment phase was still sufficiently high to procure all reinforcements made available under the VI reinforcement schedule. The removal of punishment in Cycle 2 led to a higher unpunished response rate than in Cycle 1 and thus indicates a punishment contrast i.e., a facilitative effect of punishment on later unpunished behavior (Azrin, 1960). However, the

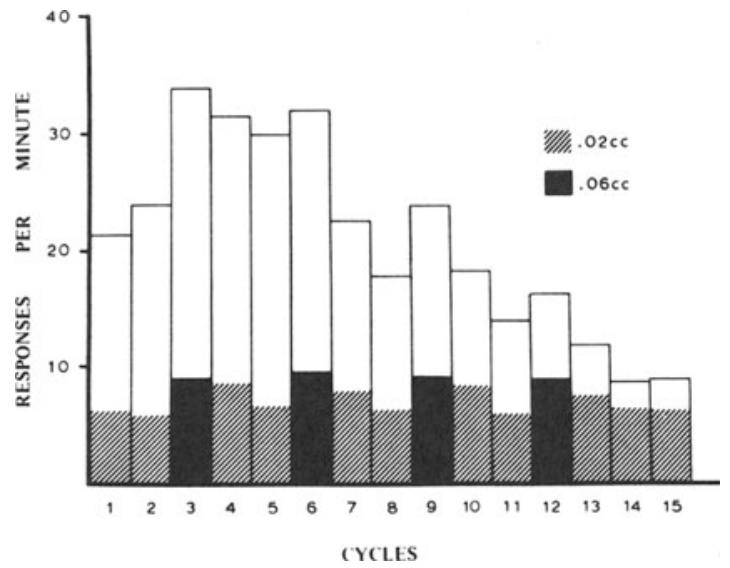

Fig. 1. Average response rates for each reinforcement-punishment cycle. 
similarity between punished response rates in Cycles 1 and 2 suggests that no contrast effects are produced by interpolating a recovery period between two punishment periods when magnitude of reinforcement is held constant.

Shifting the magnitude of reinforcement from .02 cc to $.06 \mathrm{cc}$ of water, as in Cycles $3,6,9$, and 12 , produced increased response rates during both reinforcement and punishment phases as compared to response rates in the $.02 \mathrm{cc}$ reinforcement cycles immediately preceding and succeeding the respective $.06 \mathrm{cc}$ reinforcement cycles. It should be additionally noted that rates of response for each $.02 \mathrm{cc}$ cycle following a .06 cc cycle (Cycles $4,7,10$ and 13) were higher than for the next cycle also run under $.02 \mathrm{cc}$ reinforcement (Cycles 5, 8, 11 and 14 respectively). Multiple Wilcoxon matched-pairs signed-ranks tests were separately computed from individual S's data for the reinforcement and punishment phase of each cycle and showed the above described differences to be significant $(p<.01)$.

A Friedman analysis of variance on average response rate yielded no significant differences among the four $.06 \mathrm{cc}$ punishment phases or among the four $.02 \mathrm{cc}$ cycles. A similar analysis on the unpunished response rates was significant $\left(\chi_{r^{2}}^{2}=9\right.$, df $\left.=3, p<.05\right)$. Taken together these analyses suggest that rate of responding during the reinforcement but not the punishment phase of each cycle was also dependent on the number of prior reinforcement-punishment cycles. The nature of this dependency is indicated in Fig. 1 by the over-all decrease in unpunished response rates which occurred with repeated exposures to successive reinforcementpunishment cycles.

\section{Discussion}

The direct relationship obtained between maintained response rates and reinforcement magnitude suggests that insensitivity of operant response rates to shifts in reinforcement magnitude (e.g., Keesey \& Kling, 1961; Catania, 1963) can be overcome by correlating magnitude shifts with other changes in experimental conditions. Repeated changes in experimental conditions, as used here, may serve to attenuate the behavioral control of certain potent variables (e.g., reinforcement schedule) which would otherwise prevent control of responding by different reinforcement magnitudes from being manifested. That control of behavior by a given reinforcement magnitude may persist through shifts in magnitude is indicated by the fact that response rates under $.02 \mathrm{cc}$ reinforcement were, in part, dependent on the immediately preceding reinforcement magnitude. This interaction represents a "savings effect" of reinforcement magnitude (Wagner \& Thomas, 1966), and suggests that reinforcement magnitude may control operant responding via some leamed factor $\left(r_{\mathrm{g}}-\mathrm{s}_{\mathrm{g}}\right.$ ?).

Variable-interval reinforcement schedules produce inefficient behavior in the sense that rate of response is typically higher than required to procure all available reinforcements. Indeed, the obtained punishment phase data demonstrate that a large reduction in response rate can occur without a concomitant loss in reinforcements. The repeated interpolation of punishment periods between non-punishment periods may have forced Ss to make more efficient contacts with the reinforcement parameters of the VI schedule. As such, the obtained over-all decrease in unpunished response rates may reflect the gradual transfer of this more efficient schedule control to unpunished responding.

\section{References}

AZRIN, N. H. Sequential effects of punishment. Science, 1960, 131, 605-606.

CATANIA, A. C. Concurrent performances: A baseline for the study of reinforcement magnitude. J. exp. Anal. Behav., 1963, 6, 299-300.

FERRARO, D. P. Persistence to continuous punishment as a function of amount of reinforcement. Psychon. Sci., 1966, 6, 109-110.

KEESEY, R. E., \& KLING, J. R. Amount of reinforcement and freeoperant responding. J. exp. Anal. Behav., 1961, 4, 125-132.

SHETTLEWORTH, S., \& NEVIN, J. A. Relative rate of response and relative magnitude of reinforcement in multiple schedules. $J$. exp. Anal. Behav., 1965, 8, 199-202.

WAGNER, A. R., \& THOMAS, E. Reward magnitude shifts: A savings effect. Psychon. Sci., 1966, 4, 13-14.

Note

1. This investigation was supported by National Science Foundation Grant GB 5179 . 